\title{
Comparative Study of Seismic Analysis of RCC and Composite Building with Asymmetry in Plan
}

\author{
Pavankumar Raikar and M.B. Mogali
}

\begin{abstract}
The main objective of earthquake engineers is to design and build a structure in such a way that damage to the structure during the earthquake is minimize. The paper gives the idea of seismic analysis of composite and RCC building with asymmetrical configuration. In the present work, steel-concrete composite with RCC options are considered for comparative study of G+9 storey commercial building which is situated in earthquake zone III and for earthquake loading, the provisions of IS:1893(Part1)-2002 is considered. The analysis is by carried by using ETABS Software. The parameter such as story drift, story shear and torsion is determined. For seismic analysis Equivalent static method and response spectra method is used. Seismic analysis should be performed for symmetrical as well as asymmetrical building. If the RCC and composite building have a symmetrical configurations, the torsional effect will be produce in both the building and are compared with each other to determine the efficient building under torsion. The results are compared and it is found that composite structures are better in several aspects.
\end{abstract}

Keywords--- ETABS, Equivalent Static Method, Response Spectrum Analysis.

\section{INTRODUCTION}

$\mathrm{I}^{\mathrm{N}}$ $\mathrm{N}$ India most of the building structures fall under the category of low rise buildings. So, for these structures reinforced concrete members are used widely because the construction becomes quite convenient and economical in nature. But since the population in cities is growing exponentially and the land is limited, there is a need of vertical growth of buildings in these cities. So, for the fulfillment of this purpose a large number of medium to high rise buildings are coming up these days. For these high rise buildings it has been found out that use of Composite members in construct ion is more effective and economic than using Reinforced concrete members. The popularity of steel-concrete composite construction in cities can be owed to its advantage over the conventional reinforced concrete construction. To perform well in an earthquake a high rise building should possess four main attributes namely simple and regular configuration and adequate lateral Strength, stiffness and ductility. Current earthquake codes define structural configuration as either regular or irregular in terms of size and shape of the building, arrangement of the structural and non-structural elements within the structure, distribution of mass in the building etc. A building shall be considered as irregular for the purposes of this standard, if at least one of the conditions is applicable as per IS 1893(part1):2002. This article work focuses on study of multistoried R.C.C. \&Composite building due to plan irregular buildings in ETABS software. The analysis between R.C.C and composite building involves parametric study of displacement, base shear, storey drift, lateral force. Linear static and dynamic analysis is carried out in order to know the seismic performance of R.C.C and Composite structure

\section{OBJECTIVES}

1) Modeling of multistoried R.C.C. and Steel-Concrete Composite 3-dimensional building considering plan irregularity.

2) To study various components of composite elements.

3) To analyze multistoried R.C.C. and Steel-concrete composite building by equivalent static and response spectrum method as per IS 1893(Part 1): 2002 code.

4) Comparative study of structural parameters like base shear, storey drift, displacement of both R.C.C. and Steel-concrete Composite building.

5) To study the performance of structures having plan irregularity.

\section{COMPONENTS OF COMPOSITE STRUCTURES}

Formally the multi-story buildings in India were constructed with R.C.C framed structure or Steel framed structure but recently the trend of going towards composite structure has started and growing. In composite construction the two different materials are tied together by the use of shear studs at their interface having lesser depth which saves the material cost considerably.

\section{A. Composite Slab}

A composite slab in which steel sheets are connected to the composite beam with the help of shear connectors, initially steel sheets act as permanent shuttering and also act as bottom reinforcement for steel deck slab and later it is combined with hardened concrete.
Pavankumar Raikar, Student, Dept. of Civil Engineering, SDMCET, Dharwad, India.E-mail:raikar34@gmail.com

M.B. Mogali, Assistant Professor, Dept. of Civil Engineering, SDMCET, Dharwad, India.E-mail:mbmogali@gmail.com

DOI:10.9756/BIJMMI.8179 


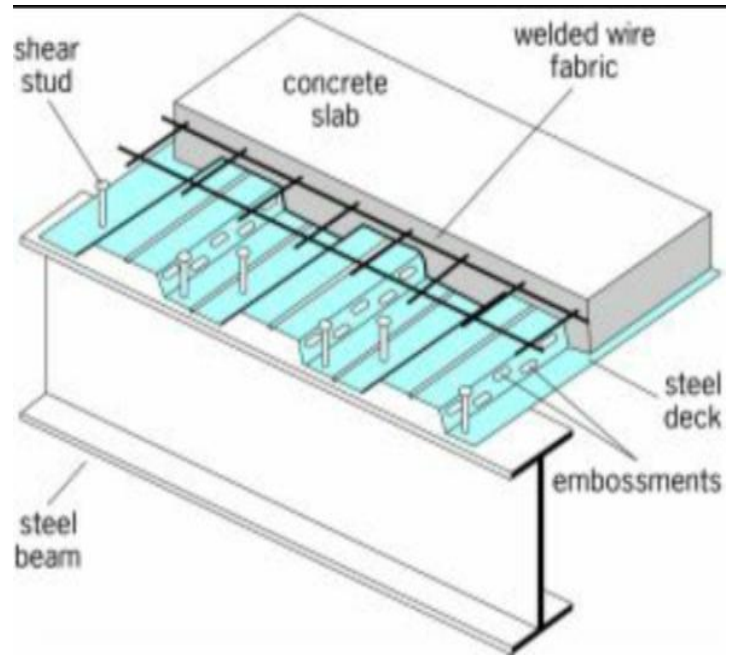

Figure 1: Composite Slab

\section{B. Shear Connectors}

Shear connectors (studs) are used to connect the concrete and structural steel and they give the sufficient strength and stiffness to the composite member

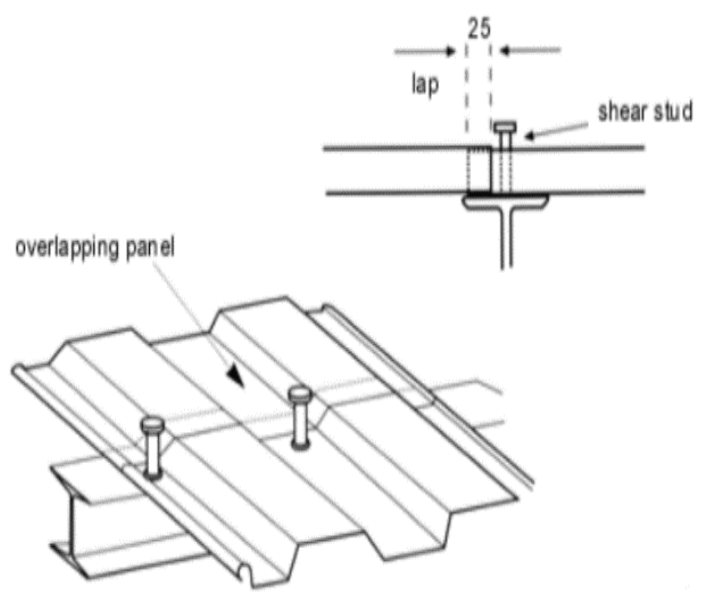

Figure 2: Shear Connectors

\section{Composite Beam}

A steel concrete composite beam consists of a steel beam, over which a reinforced concrete slab is cast with shear connectors. The composite action reduces the beam depth.

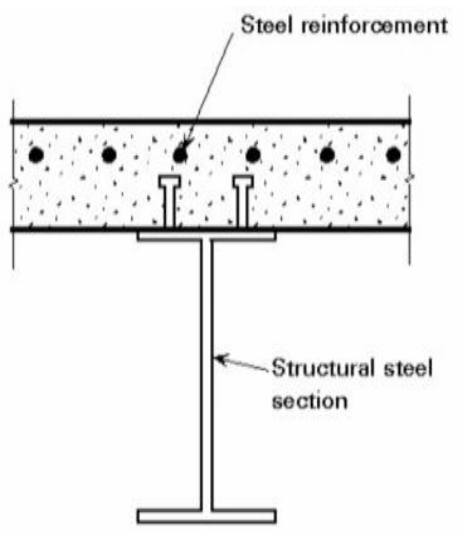

Figure 3: Composite Beam

\section{Composite Column}

Composite columns are a composite compression members or bending and compression members with steel encased sections partially or fully and concrete filled tubes.

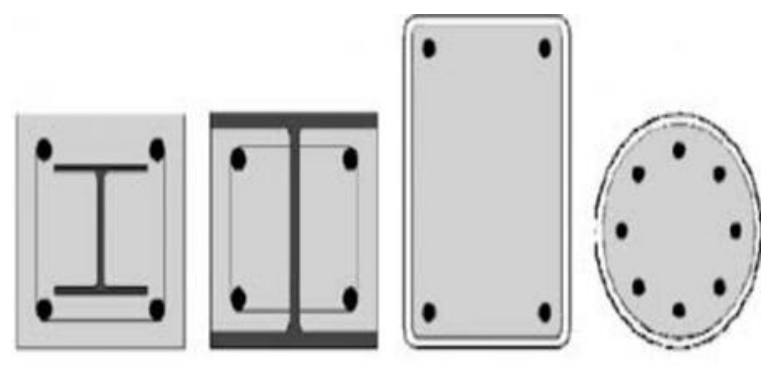

Figure 4: Composite Column

\section{CONCEPT OF REGULAR AND IRREGULAR CONFIGURATION}

To perform well in an earth quake a building should possess four main attributes namely simple and regular configuration and adequate lateral Strength, stiffness and ductility. Current earthquake codes define structural configuration as either regular or irregular in terms of size and shape of the building, arrangement of the structural and nonstructural elements within the structure, distribution of mass in the building etc. A building shall be considered as irregular for the purposes of this standard, if at least oneof the conditions is applicable as per IS 1893(part1):2002

a. Plan Irregularity Asymmetric or plan irregular structures are those in which seismic response is not only translational but also torsional, and is a result of stiffness and/or mass eccentricity in the structure. Asymmetry may in fact exist in a nominally symmetric structure because of uncertainty in the evaluation of center of mass and stiffness, inaccuracy in the measurement of the dimensions of structural
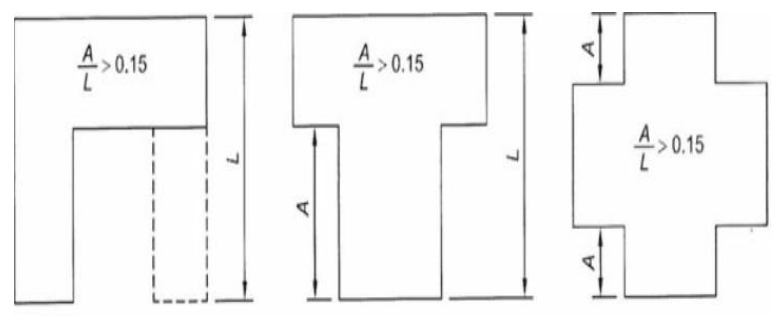

(a) Geometry

Figure 5: Plan Irregularities

b. Vertical Irregularity Vertical irregularity results from the uneven distribution of mass, strength or stiffness along the elevation of a building structure. Mass and Stiffness irregularity results from a sudden change in mass and stiffness between adjacent floors respectively. 


\section{MODELING \& ANALYSIS}

The main intention of modeling the following structures is to study the plan irregularity in R.C.C. structures in comparison with Composite structures.

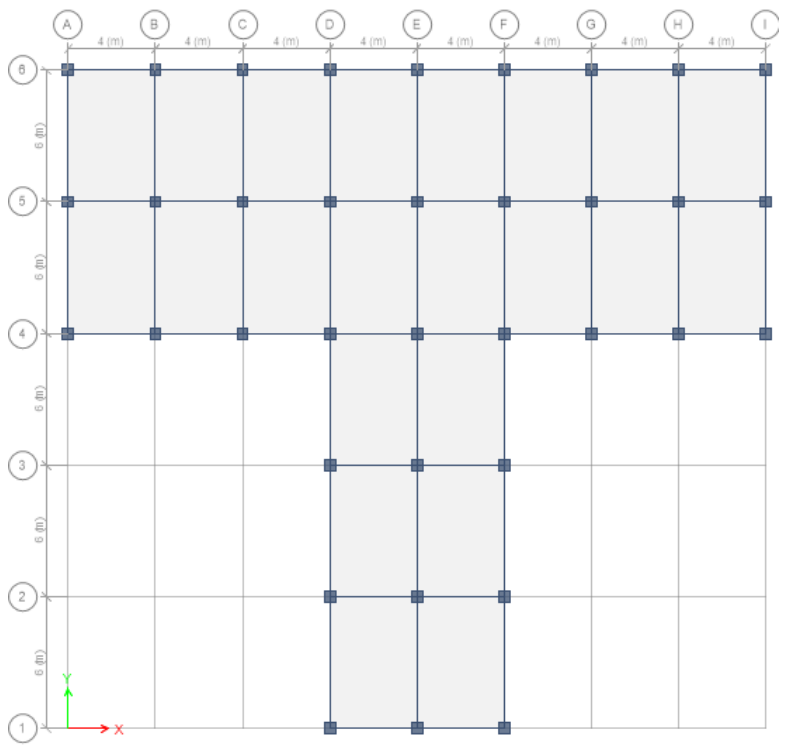

Figure 6: Plan of the Building
The structures considered here is a commercial complex building having $\mathrm{G}+9$ storey model located in seismic zone III. The plan dimension of the building is $32 \mathrm{~m} \mathrm{X} 30 \mathrm{~m}$.

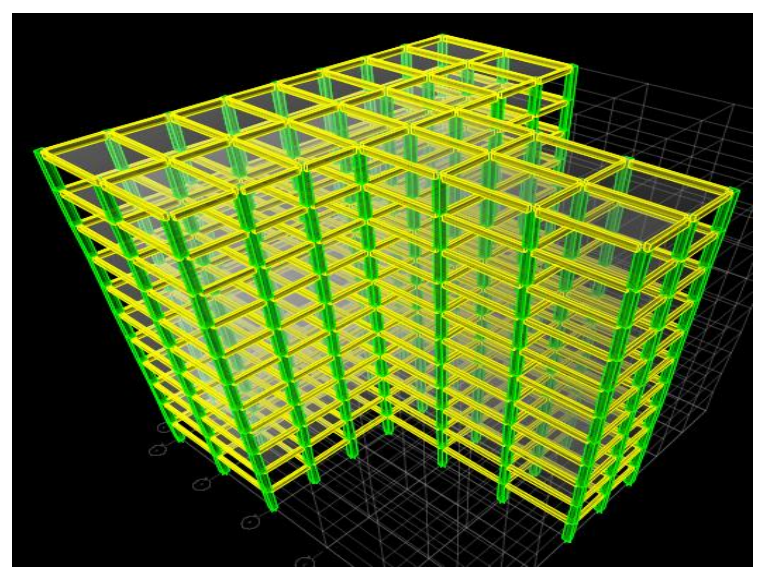

Figure 7: 3-D Elevation

Figure 6 Shows the Ground Level View from E-TABS

Height of the storey is kept as $3 \mathrm{~m}$. Depth of foundation is kept as $3 \mathrm{~m}$ including $1 \mathrm{~m}$ plinth height. Parapet Height is given as $1 \mathrm{~m}$. The study is carried out on R.C.C and Composite structures with one of the important consideration of plan irregularity in the form of $\mathrm{T}$ shape. The 3-D elevation of the building is shown in the figure 7 .

Table 1: Building Details

\begin{tabular}{|l|l|l|}
\hline Details & R.C.C & Composite \\
\hline Plan dimension & $32 \mathrm{mX} 30 \mathrm{~m}$ & $32 \mathrm{mX} 30 \mathrm{~m}$ \\
\hline Total Height of the building & $33 \mathrm{~m}$ & $33 \mathrm{~m}$ \\
\hline Height of each storey & $3 \mathrm{~m}$ & $3 \mathrm{~m}$ \\
\hline Height of parapet & $1 \mathrm{~m}$ & $1 \mathrm{~m}$ \\
\hline Depth of foundation & $3 \mathrm{~m}$ & $3 \mathrm{~m}$ \\
\hline Size of beams & $230 \mathrm{~mm}$ & ISMB 350 \\
\hline \multirow{2}{*}{ Size of outer columns } & X500mm & \\
\hline Thickness of slab & $500 \mathrm{~mm}$ & $400 \mathrm{~mm}$ \\
\hline Thickness of walls & X500mm & X400mm \\
\hline Seismic zone & $150 \mathrm{~mm}$ & $150 \mathrm{~mm}$ \\
\hline Importance factor & $230 \mathrm{~mm}$ & $230 \mathrm{~mm}$ \\
\hline Response reduction factor & $\mathrm{III}$ & $\mathrm{III}$ \\
\hline Zone factor & 1 & 1 \\
\hline Damping ratio & 5 & 5 \\
\hline Floor finish & 0.16 & 0.16 \\
\hline Live load at all floors & $5 \%$ & $2 \%$ \\
\hline Density of concrete & $1.0 \mathrm{kN} / \mathrm{m}^{2}$ & $1.0 \mathrm{kN} / \mathrm{m}^{2}$ \\
\hline Density of brick & $4.0 \mathrm{kN} / \mathrm{m}^{2}$ & $4.0 \mathrm{kN} / \mathrm{m}^{2}$ \\
\hline Density of steel & $25 \mathrm{kN} / \mathrm{m}^{3}$ & $25 \mathrm{kN} / \mathrm{m}^{3}$ \\
\hline Grade of concrete Grade of reinforcing steel Soil condition & $20 \mathrm{kN} / \mathrm{m}^{3}$ & $20 \mathrm{kN} / \mathrm{m}^{3}$ \\
\hline Grade of reinforcing steel & $\ldots$ & $7850 \mathrm{~kg} / \mathrm{m}^{3}$ \\
\hline Grade of structural steel & Fe 415 & $\mathrm{M} 20$ \\
\hline Soil condition & $\ldots$ & $\mathrm{Fe} 415$ \\
\hline & $\mathrm{Medium} \mathrm{Soil}$ & $\mathrm{Medium} \mathrm{Soil}$ \\
\hline
\end{tabular}




\section{RESULTS \& DISCUSSIONS}

\section{A. Displacement}

- Joint Displacement in X-direction

Table 2: Displacements in $\mathrm{mm}$ along $\mathrm{X}$ Direction

\begin{tabular}{|c|c|c|c|c|}
\hline Story & RSX COMP & EQXCOMP & $R S X R C C$ & $E Q X R C C$ \\
\hline Base & 0 & 0 & 0 & 0 \\
\hline Story1 & 2.9 & 2.9 & 2.7 & 2.5 \\
\hline Story2 & 8.5 & 8.7 & 7 & 7.1 \\
\hline Story3 & 14.6 & 15.6 & 11.5 & 12 \\
\hline Story4 & 20.7 & 22.8 & 15.8 & 17.1 \\
\hline Story5 & 26.3 & 29.8 & 19.7 & 22 \\
\hline Story6 & 31.4 & 36.4 & 23.3 & 26.7 \\
\hline Story7 & 35.8 & 42.5 & 26.4 & 31 \\
\hline Story8 & 39.6 & 47.8 & 29.1 & 34.8 \\
\hline Story9 & 42.6 & 52.1 & 31.3 & 37.9 \\
\hline Story10 & 44.8 & 55.3 & 32.9 & 40.3 \\
\hline Story11 & 46.2 & 57.4 & 34 & 41.8 \\
\hline
\end{tabular}

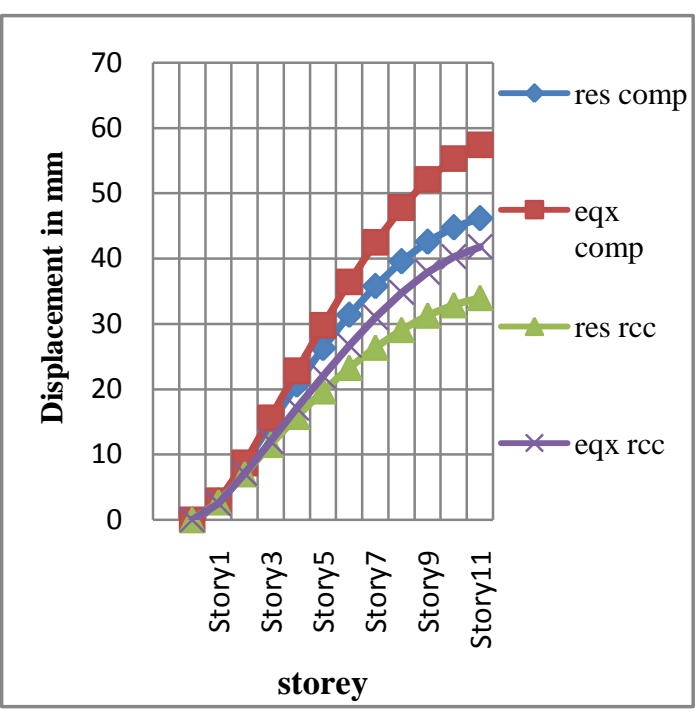

Figure 8: Displacements in $\mathrm{X}$ direction

- Joint Displacement in Y-direction

Table 3: Displacements in mm along Y Direction

\begin{tabular}{|l|l|l|l|l|}
\hline Story & RSYCOMP & EQYCOMP & RSYRCC & EQYRCC \\
\hline Base & 0 & 0 & 0 & 0 \\
\hline Story1 & 3.5 & 3.6 & 3.1 & 3.2 \\
\hline Story2 & 10.5 & 11.2 & 8.6 & 8.9 \\
\hline Story3 & 18.6 & 20.3 & 14.5 & 15.4 \\
\hline Story4 & 26.6 & 29.8 & 20.1 & 21.9 \\
\hline Story5 & 34 & 39.3 & 25.1 & 28.3 \\
\hline Story6 & 40.8 & 48.2 & 29.7 & 34.3 \\
\hline Story7 & 46.7 & 56.4 & 33.7 & 39.8 \\
\hline Story8 & 51.6 & 63.4 & 37 & 44.6 \\
\hline Story9 & 55.5 & 69.2 & 39.6 & 48.5 \\
\hline Story10 & 58.4 & 73.4 & 41.4 & 51.2 \\
\hline Story11 & 60.3 & 76.2 & 42.5 & 52.9 \\
\hline
\end{tabular}

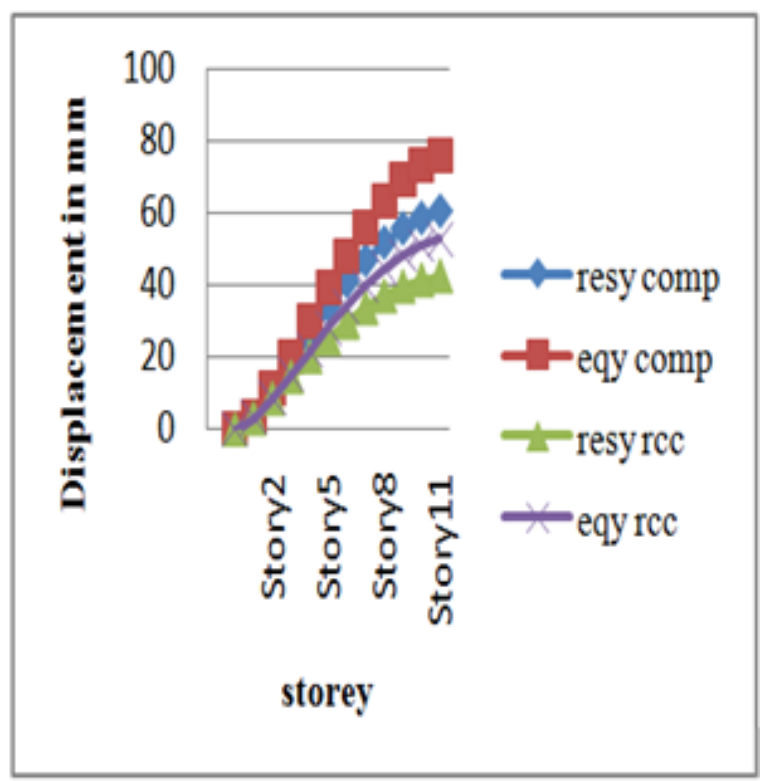

Figure 9: Displacements in Y direction

The above Tables and Figures show values of joint displacements for structures having Plan irregularity. Composite structures represent higher values of displacement than R.C.C structures. Joint displacement in X-direction in RCC structures is reduced by $25.3 \%$ and $26.42 \%$ after analyzing by both Equivalent static and Response spectrum analysis respectively. Similarly in Y-direction it reduced by $29.5 \%$ and $30.6 \%$ respectively

\section{B. Base Shear}

Table 4: Base shear in $\mathrm{kN}$

\begin{tabular}{|l|l|}
\hline Type of structure & Base shear $(\mathrm{KN})$ \\
\hline R.C.C. & 1768.977 \\
\hline composite & 1521.7031 \\
\hline
\end{tabular}

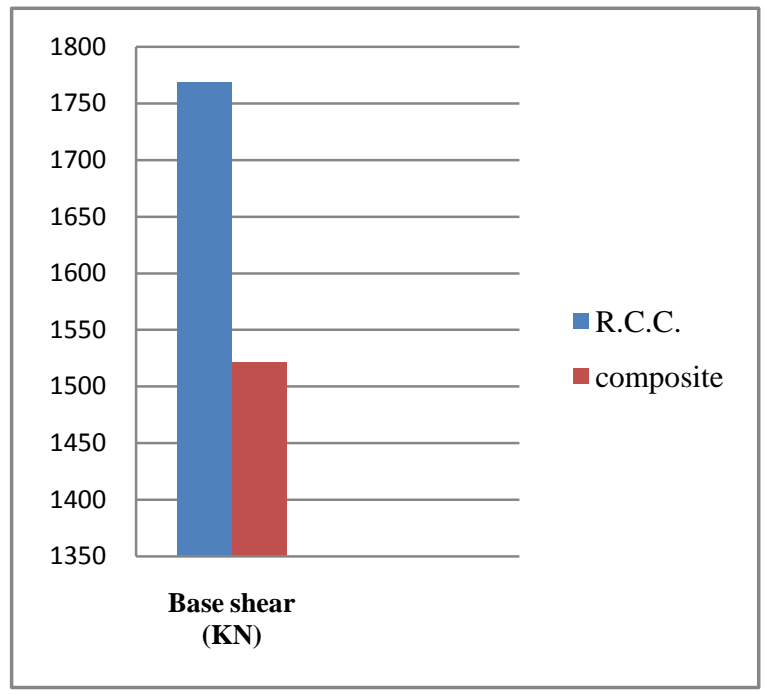

Figure 10: Base Shear

Table 4 and Figure 10 shows Design base shear Values. Design base shear obtained for composite structures having plan irregularity is decreased by $14 \%$. 


\section{Self-Weight}

Table 5: Self Weight (in kN) For RCC and Composite Models

\begin{tabular}{|c|c|}
\hline Type of Structure & Self-weight (KN) \\
\hline R.C.C. & 74411.97 \\
\hline Composite & 61764.702 \\
\hline
\end{tabular}

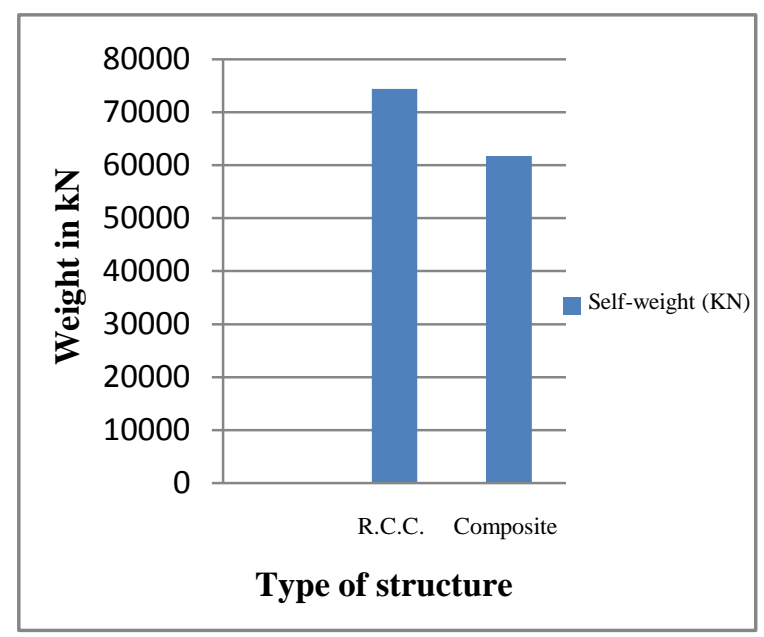

Figure 11: Self-weight

Table 5 and Figure 11 represent self-weight of structures. Composite Structures having plan irregularity the self-weight is decreased by $17 \%$

\section{Axial Force}

Table 6: Axial Force (in kN) for Corner Column

\begin{tabular}{|c|c|}
\hline \multicolumn{2}{|c|}{ Axial force of corner columns in $\mathrm{kN}$} \\
\hline RCC & 645.16 \\
\hline COMPOSITE & 351.17 \\
\hline
\end{tabular}

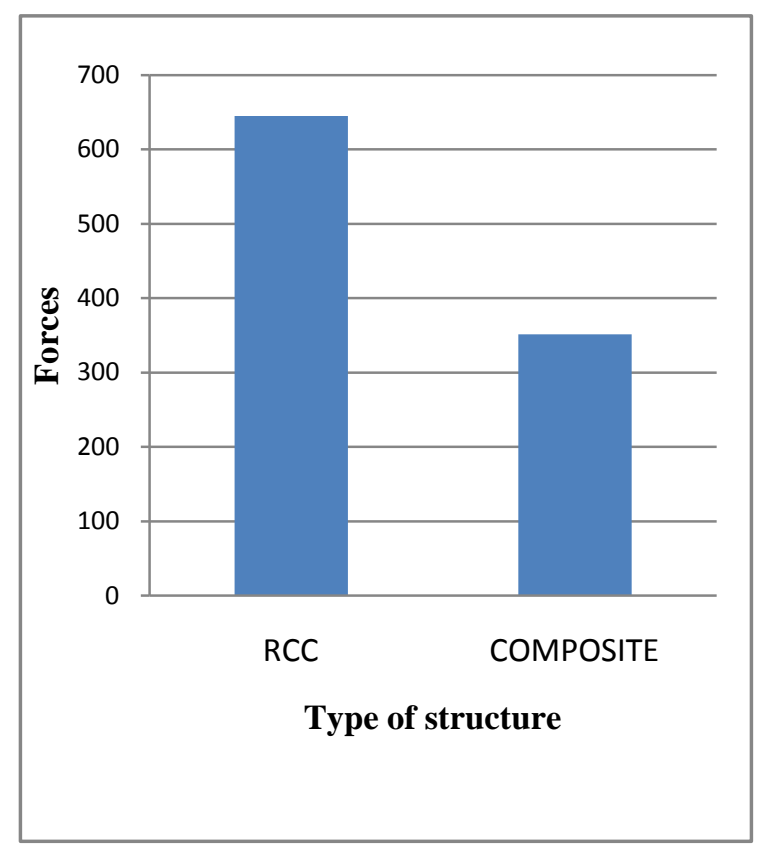

Figure 12: Axial Forces in Column

Table 6 and Figure 12 represent axial force for the corner columns of the structures. The axial force of Composite Structures is reduced by $45 \%$.
E. Torsion

\begin{tabular}{|l|l|}
\hline \multicolumn{2}{|l|}{ Maximum torsion for corner columns kN-m } \\
\hline RCC & 3.521 \\
\hline COMPOSITE & 4.473 \\
\hline
\end{tabular}

Maximum torsion for RCC building is found to 3.521

$\mathrm{KN}-\mathrm{m}$ and for steel building it is found to be $4.473 \mathrm{KN}-\mathrm{m}$

\section{CONCLUSION}

1) The plan configurations of structure has significant impact on the seismic response of structure in terms of displacement, story drift, story shear

2) The displacement (deflection) and storey drift in R.C.C. Structure is merely less than composite structure but are in permissible limit as prescribed by the codal pro- visions. It is due to the flexibility of composite structure when compared to RCC structures

3) Large displacement was observed in the $T$ shape building. It indicates that building with severe irregularity shows maximum displacement and storey drift

4) Weight of composite structure is quite low as compared to RCC structure which helps in reducing the foundation cost

5) The axial forces in RCC structure is on higher side of composite structure.

6) Maximum torsion for RCC building is found to be lesser than steel building, thus from the above results RCC building appears to be more efficient in torsion than composite building

7) Composite structures are the best solution for high rise structure as compared to RCC structure.

\section{REFERENCES}

[1]. D.R. Panchal and P.M. Marathe, "Comparative study of R.C.C., Steel and Composite building", Institute Of Technology, Nirma University, Ahmedabad-382481, Pp. 08-10, 2011.

[2]. M.S. Kumawat and L.G. Kalurkar, "Analysis And Design Of Multistory Building Using Composite Structure", International Journal of Structural and Civil Engineering Research (IJSCER), Vol. 3, No. 2 Pp. 126-137, 2014.

[3]. Pardeshi sameer and N.G. Gore, "Study of seismic analysis and design of multi storey symmetrical and asymmetrical building", International Research Journal of Engineering and Technology, Vol. 03, 2016.

[4]. IS 456:2000, "Indian Standard code of practice for Plain and Reinforced concrete", Bureau of Indian Standards, New Delhi, India.

[5]. IS 11384:1985, "Code of Practice for Design of Composite Structure", Bureau of Indian Standards, New Delhi, India.

[6]. IS: 11384, Code of practice for composite construction in structural steel and concrete, Bureau of Indian Standards, New Delhi, 1985. 